\title{
Psychological well-being remaja dari keluarga broken home
}

\author{
Ifdil Ifdil $^{\left.1^{*}\right)}$, Indah Permata Sari ${ }^{2}$, Viqri Novielza Putri ${ }^{2}$ \\ ${ }^{1}$ Indonesian Institute for Counseling, Education and Therapy (IICET), Indonesia \\ ${ }^{2}$ Fakultas Ilmu Pendidikan, Universitas Negeri Padang, Indonesia \\ *) Correspondence: ifdil@konselor.org
}

\begin{abstract}
Keluarga merupakan unit kehidupan terkecil di masyarakat yang terdiri dari ayah, ibu dan anak, tetapi keluarga menempati kedudukan yang primer dan fundamental. Setiap anak tentunya mendambakan kondisi keluarga yang harnomis, namun dalam kehidupan keluarga tidak lepas dari badai kehidupan yang turut mempengaruhinya sehingga membuat kondisi keluarga mengalami keretakan. Keretakan hubungan orangtua ini membuat kondisi dalam keluarga menjadi broken home yang mana kondisi tersebut memiliki pengaruh terhadap kesejahteraan psikologis remaja. Kesejahteraan psikologis merupakan suatu kondisi menjadi sejahtera dengan sikap-sikap seperti penerimaan diri, bertujuan, hubungan positif, pribadi mandiri, dan bertumbuh. Remaja dengan kondisi keluarga broken home tentu ini tidak mudah karena mereka berada pada kondisi penuh tekanan yaitu harus menyesuaikan diri dengan lingkungannya dan mengalami perubahan-perubahan pada diri dan kehidupan mereka, sebagai remaja hendaknya perlu mencapai kesejahteraan psikologis yang baik agar dapat mencapai tugas-tugas perkembangannya.
\end{abstract}

Keywords: Psychological well-being, remaja, keluarga broken home

Article History: Received on 28/02/2020; Revised on 24/03/2020; Accepted on 19/04/2020; Published Online: 23/05/2020.

This is an open access article distributed under the Creative Commons Attribution License, which permits unrestricted use,
distribution, and reproduction in any medium, provided the original work is properly cited. (C)2020 by author.

\section{PENDAHULUAN}

Keluarga merupakan unit kehidupan terkecil di masyarakat (Busra, 2019; Kertapati, 2019; Na'imah, 2019)yang terdiri dari ayah, ibu dan anak (Muthahari, 2019; Sodikin, 2019), tetapi keluarga menempati kedudukan yang primer dan fundamental. Keluarga merupakan titik pangkal kehidupan seseorang, sumber perawatan dengan kasih sayang, pendidikan pertama bagi anak-anak baik menanamkan nilai-nilai kehidupan (Donnalo, 2020) maupun sosial (Asiyah, 2017; Zulhaini, 2019). Selain itu keluarga wajib untuk menjamin kesejahteraan anggota keluarganya (Ischak, 2019), bukan hanya dari segi materi namun juga dari segi psikologisnya. Senada dengan itu (Sobur, 1991) menyatakan pada hakikatnya "keluarga merupakan tempat pertama bagi anak untuk memperoleh pembinaan mental dan pembentukan kepribadian". 
Menurut Undang-undang No. 23 Tahun 2002 Pasal 26 tentang Perlindungan Anak bahwa orangtua berkewajiban dan bertanggung jawab untuk mengasuh, memelihara, mendidik, dan melindungi anak, menumbuhkembangkan anak sesuai dengan kemampuan, bakat dan minatnya serta mencegah terjadinya perkawinan pada usia anakanak. Setiap anak tentunya mendambakan keluarga yang lengkap (ayah, ibu dan anak) dalam satu tempat tinggal yang dipenuhi dengan kebahagian (Soraya, 2013), menjalankan perannya sehingga terciptanya kehidupan keluarga yang sejahtera dan harmonis. Namun, dalam kehidupan keluarga tidak lepas dari badai kehidupan yang turut mempengaruhinya sehingga membuat kondisi keluarga menjadi disharmonis bahkan berujung pada perpisahan atau perceraian.

Menurut (Hasan, 2012) dari berbagai bentuk masalah yang timbul di dalam kehidupan keluarga dapat menjadi benih yang mengancam kehidupan perkawinan bahkan akan berakibat pada keretakan rumah tangga bahkan hingga perceraian. Menurut (Goode, 2007) broken home merupakan kondisi retaknya suatu struktur keluarga karena salah satu atau beberapa anggota keluarga gagal menjalankan kewajiban peran mereka karena perceraian, meninggalkan rumah, pertengkaran atau tidak memperlihatkan kasih sayang lagi dalam keluarga.

Remaja dengan kondisi keluarga broken home (Pratama, Syahniar, \& Karneli, 2016) tentu ini tidak mudah karena mereka berada pada kondisi penuh tekanan (Aziz, 2019) yaitu harus menyesuaikan diri dengan lingkungannya dan mengalami perubahanperubahan pada diri dan kehidupan mereka. Selanjutnya Santrock (2003) remaja-remaja yang berasal dari keluarga tidak utuh/ broken home memperlihatkan penyesuaian diri yang buruk dibandingkan dengan remaja-remaja yang berasal dari keluarga yang utuh. Hal tersebut ditandai dengan permasalahan akademis, penyimpangan perilaku, kecemasan dan depresi, kurang memiliki tanggung jawab sosial, kurang kompeten dalam hubungan sosial dan cenderung bergabung dengan teman sebaya yang anti sosial. Tentunya akibat dari keretakan hubungan orangtua ini membuat kondisi dalam keluarga menjadi broken home yang mana kondisi tersebut memiliki pengaruh terhadap kesejahteraan psikologis remaja, ditandai dengan remaja yang berasal dari keluarga yang tidak utuh memiliki kesejehateraan psikologis yang rendah.

Menurut Bradburn (Ryff, C. D, Keyes, 1995) kesejahteraan psikologis yaitu individu mampu menerima diri apa adanya, tidak terdapat gejala-gejala depresi dan selalu memiliki tujuan hidup yang dipengaruhi oleh fungsi psikologi positif yang berupa aktualisasi diri, penguasaan lingkungan. Kondisi psychological well-being remaja perlu diperhatikan, karena jika remaja merasa sejahtera dan bahagia tentunya akan berdampak pada kehidupan remaja (Linawati \& Desiningrum, 2018). Remaja yang mampu menerimaan keadaan masa lalunya akan lebih mampu untuk menerima kelebihan dan kekurangannya (Ramadhani, Djunaedi, \& Sismiati, 2016). Sehingga akan memandang masa depan secara positif. Senada dengan itu menurut (C. D Ryff, 1989) mengatakan kesejahteraan psikologis yaitu sebuah kondisi dimana individu memiliki sikap yang positif terhadap diri sendiri dan orang lain, dapat membuat keputusan sendiri dan mengatur lingkungan yang kompatibel dengan kebutuhannya, memiliki tujuan hidup dan membuat hidup mereka lebih bermakna, serta berusaha mengekplorasi dan mengembangkan dirinya. 
Dari definisi di atas dapat disimpulkan Psychological well-being merupakan persepsi individu terhadap pengalaman hidupnya. Well-being ini menjadi kandasan hidup dan standar dalam menikmati hidup. Apabila well-being individu kurang baik, ia akan menilai dirinya buruk. Pengalaman hidupnya buruk, cara menilai hidup buruk, motivasi untuk mengubah hidup pun buruk (Bradburn, 1998)

Salah satu faktor yang mempengaruhi kesejahteraan psikologis (psychological wellbeing), yakni dukungan sosial yang diartikan sebagai rasa nyaman, perhatian, penghargaan atau pertolongan yang dipersepsikan oleh seseorang individu yang didapat dari berbagai sumber, diantaranya pasangan, keluarga, teman, rekan kerja, maupun organisasi sosial (C. D Ryff, 1989). Dengan adanya dukungan sosial dapat menumbuhkan perasaan dicintai (Ermayanti \& Abdullah, 2007), dihargai, diperhatikan, dan sebagai bagian dari suatu jejaring sosial, seperti organisasi masyarakat dalam individu. Pada remaja yang berasal dari kondisi keluarga broken home cenderung tidak memperoleh perhatian dari orangtuanya karena sudah terpisahnya tempat tinggal antara ayah dan ibu. Senada dengan itu (Indriani, 2008) menyatakan bahwa perhatian dan kasih sayang orangtua pada anak dapat menurun apabila terjadi konflik dalam rumah tangga dan berujung pada perceraian. Santrock (2003) menjelaskan psikologis menjadi dampak utama yang melekat hingga usia dewasa awal dari keluarga yang broken home. Akibat dari keluarga yang broken home berdampak pada kesejahteraan psikologis remaja.

Dari hasil penelitian yang dilakukan oleh (Ramadhani et al., 2016) bahwa pada 33 orang remaja SMKN 26 Pembangunan Jakarta yang orangtuanya bercerai menunjukkan bahwa 52\% remaja memiliki kesejahteraan psikologis yang rendah. Penelitian yang dilakukan Herdian (2016) dari 29 orang remaja yang orangtuanya bercerai sebanyak $66 \%$ remaja mengaku tidak konsentrasi dalam belajar hal ini menandakan remaja yang orangtuanya bercerai memiliki kesejahteraan psikologis yang rendah dalam dimensi penerimaan diri, remaja merasa kecewa dengan keadaan yang dialaminya sehingga tidak dapat menyesuaikan diri dengan keadaan sekarang sehingga membuatnya sulit berkonsentrasi dalam belajar. Senada dengan itu, hasil penelitian menunjukkan bahwa individu yang mendapatkan dukungan sosial dari keluarga memiliki kondisi psychological well-being yang lebih baik daripada yang tidak mendapatkan dukungan sosial (Riandana, 2016). Namun kondisi keluarga yang broken home akibat perceraian justru menyebabkan remaja kesulitan mendapatkan dukungan dari orangtuanya (Nasri, Nisa, \& Karjuniwati, 2018). Hal ini didukung oleh hasil penelitian (Wells, 2010) yang menyebutkan bahwa kebersamaan dengan orangtua dapat menimbulkan perasaan yang lebih positif dan meningkatkan psychological well being seorang anak. Kondisi keluraga broken home secara psikologis memberikan kontribusi negatif terhadap perkembangan remaja. Berdasarkan uraian di atas dapat diperoleh gambaran mengenai kontribusi negatif kondisi keluarga broken home terhadap kesejahteraan psikologis remaja.

\section{PSYCHOLOGICAL WELL-BEING}

Setiap individu berusaha untuk memenuhi kebutuhan psikologis agar hidupnya menjadi sejahtera. Istilah Psychological well-being merupakan sebutan bagi kesejahteraan (well-being) psikologis manusia. Menurut (C. D Ryff, 1989) psychological well-being 
merupakan istilah yang digunakan untuk menggambarkan kesehatan psikologis individu berdasarkan pemenuhan kriteria fungsi psikologi positif. Selanjutnya dinyatakan bahwa psychological well-being merupakan pencapaian penuh dari potensi psikologis seseorang. Individu yang memiliki kesejahteraan psikologis dapat menerima segala kekuatan dan kelemahan yang ada di dalam dirinya menciptakan hubungan yang positif dengan orang lain disekitarnya (Pangastuti \& Sawitri, 2015), memiliki kemampuan untuk mengambil keputusan dan mandiri (Harimukthi \& Dewi, 2017), mampu dan berkompetensi untuk mengatur lingkungan (Awaliyah \& Listiyandini, 2017; Indryawati, 2014; Prabowo, 2016), memiliki tujuan hidup (Harimukthi \& Dewi, 2017), dan merasa mampu untuk melalui tahapan perkembangan dalam kehidupannya(Harimukthi \& Dewi, 2017; Prabowo, 2016).

Psychological well-being adalah suatu kondisi psikologis yang positif yang ditandai dengan adanya kemampuan individu untuk menerima dirinya apa adanya, mampu membentuk hubungan dengan orang lain, memiliki otonomi, memiliki tujuan hidup, mampu menguasai lingkungan eksternal serta mampu merealisasikan dirinya (Papalia, Olds, \& Feldman, 2008). Bila remaja tidak mencapai kesejahteraan psikologisnya maka dia tidak akan berfungsi dengan baik di dalam masyarakat.

Senada dengan itu (Ryff, C. D, Keyes, 1995) menyatakan Psychological well-being adalah konsep dari kesejahteraan psikologis individu yang mampu menerima diri apa adanya, tidak terdapat gejala-gejala depresi, dan selalu berorientasi pada tujuan hidup yang dipengaruhi oleh fungsi psikologi postif berupa aktualisasi diri, penguangasaan diri dan penguasaan lingkungan sosial. Selanjutnya Bradburn (Ryff, C. D, Keyes, 1995) menyatakan Psychological well-being merujuk kepada segala aktivitas yang dilakukan oleh individu yang berlangsung setiap hari dimana dalam proses tersebut kemungkinan mengalami fluktuasi pikiran dan perasaan yang dimulai dari kondisi mental negatif kepada kondisi mental yang positif.

Dari pernyataan para ahli di atas dapat disimpulkan kesejahteraan psikologis (psychological well-being) merupakan keadaan psikologis yang positif pada diri individu ditandai dengan menerima diri apa adanya baik kekurangan maupun kelebihan, mampu menciptakan hubungan yang positif dan harmonis dengan orang lain, mampu mengambil keputusan secara mandiri, memiliki orientasi kehidupan, dan mampu melalui tahap-tahap perkembangan dalam hidupnya merealisasikan segala tuntutan perkembangan.

\section{KELUARGA BROKEN HOME}

Keluarga adalah kesatuan terkecil dalam masyarakat yang terdiri dari ayah, ibu dan anak. Secara etimologi broken home diartikan sebagai keluarga retak (Echolis, 2020). Broken home adalah kondisi keluarga yang tidak normal (Hasanah, Sahara, Sari, Wulandari, \& Hutasuhut, 2017) dan mengalami krisis rumah tangga di dalamnya (Bupu, Nawaji, \& Iswahyudi, 2019; Rofiqah \& Sitepu, 2019; Willis, 2013) menggambarkan keluarga yang tidak utuh (Chaplin, 2011). Broken home dimaknai sebagai kondisi dimana struktur keluarga yang sudah tidak lengkap lagi (Aritonang, 2019) terjadi akibat dari perpecahan suatu unit keluarga, terputus atau retaknya struktur keluarga, sehingga fungsi dari keluarga tidak bejalan dengan baik. Hal yang membuat keluarga menjadi retak yaitu akibat kematian, kondisi ekonomi, perbedaan pendapat, kurangnya komunikasi dan 
terlalu mementingkan ego. Senada dengan itu bahwa broken home terjadi apabila struktur keluarga itu tidak utuh lagi, misalnya karena kematian salah satuorang tua atau perceraian, kehidupan keluarga tidak harmonis lagi (Willis, 2013; Yunistiati, Djalali, \& Farid, 2014).

Berdasarkan beberapa pendapat di atas, dapat disimpulkan bahwa broken home adalah kondisi keluarga yang mengalami krisis rumah tangga didalamnya sehingga membuat retaknya struktur di dalam keluarga dan broken home tidak hanya dimaknai dengan perceraian kedua orang tua, tetapi ketidak seimbangan peran dan berkurangnya salah satu fungsi keluarga juga bisa dikatakan broken home.

\section{ASPEK-ASPEK PSYCHOLOGICAL WELL-BEING}

Ryff (1989) menyatakan bahwa Psychological well-being terdiri dari enam dimensi, ketika keenam dimensi tersebut terpenuhi maka individu akan memiliki tingkat psychological well-being yang baik. Keenam aspek tersebut yakni:

1. Self-acceptance (penerimaan diri)

Aspek ini ditandai dengan sikap positif pada dirinya sendiri, mengenali, memahami, mengakui dan menerima diri termasuk kekuatan dan kelemahannya.

2. Positive relations with other (hubungan baik dengan orang lain)

Aspek ini ditandai dengan adanya hubungan hangat, memuaskan, saling percaya, memiliki empati, kasih sayang yang kuat serta dapat memahami dan menerima hubungan dengan manusia lain.

3. Autonomy (Otonomi)

Aspek ini menggambarkan individu dapat mengatur perilaku dari dalam dirinya, berupaya untuk tidak bergantung atau mandiri, dan melakukan evaluasi diri berdasarkan standar pribadinya.

4. Environmental mastery (Memahami lingkungan )

Aspek ini menggambarkan individu memiliki rasa pemahaman dan kompetensi dalam mengelola lingkungan, mampu mengontrol berbagai aktivitas eksternal yang kompleks, dan mampu memanfaatkan peluang di sekitar.

5. Purpose in life (Tujuan hidup)

Aspek ini menggambarkan individu dengan arah tujuan hidup yang jelas, merasa ada makna atas kehidupannya, dan berkeyakinan tinggi atas tujuan hidupnya.

6. Personal growth (Pengembangan diri)

Aspek ini ditandai dengan individu memiliki perasaan untuk terus berkembang, terbuka terhadap pengalaman baru, dan sadar akan potensi yang dimiliki.

Berdasarkan penjelasan di atas bahwa ketercapaian psychological well being pada remaja dari keluarga broken home ditandai dengan berfungsinya ke enam aspek-aspek psikologis positif dalam psychological well-being yang meliputi self-acceptance, positive relationship with other, autonomy, environmental mastery, purpose in life, dan personal growth. dalam prosesnya mencapai aktualisasi diri. Psychological well being akan dicapai individu apabila dia mampu mencapai atau mewujudkan kebahagiaan disertai pemaknaan hidup (Viitpoom \& Saat, 2016). 


\section{FAKTOR-FAKTOR YANG MEMPENGARUHI PySCHOLOGICAL WELL-BEING}

Menurut (Carol D Ryff \& Keyes, 1995) terdapat beberapa faktor yang dapat mempengaruhi kesejahteraan psikologis (psychological well-being) seseorang, antara lain:

1. Faktor Demografis

Secara faktor demografis yang mempengaruhi kesejahteraan psikologis mencakup usia, jenis kelamin, status sosial ekonomi dan budaya.

2. Dukungan Sosial

Dukungan sosial diartikan sebagai rasa nyaman, perhatian, penghargaan atau pertolongan yang dipersepsikan oleh seseorang individu yang didapat dari berbagai sumber, diantaranya pasangan, keluarga, teman, rekan kerja, maupun organisasi sosial. Dengan adanya dukungan sosial dapat menumbuhkan perasaan dicintai, dihargai, diperhatikan, dan sebagai bagian dari suatu jejaring sosial, seperti organisasi masyarakat dalam individu.

3. Evaluasi terhadap Pengalaman Hidup

Pengalaman hidup mencakup berbagai bidang kehidupan dalam berbagai periode kehidupan. Evaluasi individu terhadap pengalaman hidupnya memiliki pengaruh yang penting terhadap kesejahteraan psikologis. Individu akan melihat masa lalunya sebagai peluang untuk lebih baik lagi.

4. Locus of Control (LOC)

Locus of Control didefinisikan sebagai suatu ukuran harapan umum seseorang mengenai pengendalian (kontrol) terhadap penguatan (reinfocement) yang mengikuti perilaku tertentu, dapat memberikan peramalan terhadap kesejahteraan psikologis.

Sedangkan (Schmutte \& Ryff, 1997) mengemukakan faktor-faktor yang mempengaruhi kesejahteraan psikologis (psychological well-being) meliputi kepribadian, pekerjaan, dan kesehatan dan fungsi fisik.

Berdasarkan penjelasan di atas, dapat disimpulkan bahwa faktor-faktor yang mempengaruhi kesejahteraan psikologis (psychological well-being) individu meliputi usia, jenis kelamin, status sosial ekonomi, budaya, kepribadian, kesehatan dan fungsi fisik. Apabila faktor-faktor tersebut berfungsi dengan baik maka akan mendukung kesejahteraan psikologis individu, namun sebaliknya apabila tidak berfungsi dengan baik maka dapat menyebabkan rendahnya kesejahteraan psikologis individu.

\section{IMPLIKASI DALAM LAYANAN BIMBINGAN DAN KONSELING}

Fenomena yang ditemukan pada remaja yang berasal dari keluarga broken home mereka akan merasa sedih, malu, minder karena keretakan yang terjadi dalam keluarganya. Tekanan dan keadaan lingkungan yang mengaruskan remaja menyesuaikan dengan lingkungan sebagai akibat dari kondisi kedua orangtuanya membuat remaja merasa dirinya berbeda dengan orang lain, sehingga mengalami diskriminasi dari lingkungan sosial dan membuat kesejahteraan psikologis remaja menjadi rendah. Menurut (Yusuf, 2009) Psychological well-being pada dasarnya termasuk salah satu tujuan dari layanan bimbingan dan konseling, yakni memberikan bantuan kepada siswa agar mencapai kehidupan yang bermakna dan berbahagia baik secara personal maupun sosial. 
Perasaan bahagia, menyenangkan, serta memuaskan merupakan hal yang dihasilkan dari psycological well-being.

Meningkatkan kesejahteraan psikologis remaja yang orangtuanya bercerai memerlukan upaya-upaya penanggulangan dengan memanfaatan layanan bimbingan dan konseling untuk dapat membantu remaja menjadi kehidupan efektif sehari-hari. Menurut (Yuliani, 2018) layanan bimbingan dan konseling sebagai upaya peningkatan psychological well-being pada remaja dari keluarga broken home dapat diperkuat melalui aspek-aspek pribadi-sosial. Ada beberapa layanan yang dapat membantu remaja dalam meningkatkan kesejahteraan psikologisnya yaitu:

1. Layanan Informasi

Menurut (Prayitno \& Amti, 2004) layanan informasi berusaha memenuhi kekurangan individu akan informasi yang mereka butuhkan. Layanan informasi individu diberikan informasi dan pemahaman baru yang nantinya dapat digunakan untuk kepentingan hidup dan perkembangannya. Layanana yang diberikan seperti kosentrasi belajar dan menerima keadaan keluarga dengan ikhlas tanpa berpikir seandainya terlahir dari keluarga bahagia melalui layanan informasi (Hasanah et al., 2017).

2. Layanan Konseling Individual

Layanan konseling individual adalah layanan yang diberikan langsung oleh guru BK/ konselor kepada remaja yang mengalami permasalahan pribadi dan membantu dalam mengetaskan permasalahan tersebut (Prayitno, 2012). Dalam kegiatan layanan konseling individual guru BK/ konselor dapat membahas permasalahan yang dialami oleh remaja yang menyebabkan terganggunya kesejahteraan psikologisnya.

3. Layanan Bimbingan Kelompok

Layanan bimbingan kelompok merupakan layanan yang diberikan kepada sejumlah orang yang akan membahas salah satu topik yang umum sehingga anggota kelompok mendapat wawasan dan pengetahhuan baru dari topik yang dibahas dengan adanya dinamika kelompok (Prayitno, 2012). Layanan bimbingan kelompok dapat digunakan oleh Guru BK/ Konselor untuk menambah wawasan dalam menyikapi hal-hal yang dirasa penting dan hangat untuk diperbincangkan, beberapa topik dapat digunakan agar individu menjadi yakin terhadap kemampuan dirinya, dapat menerima diri dan menguasai lingkungan.

4. Layanan Konseling Kelompok

Layanan konseling kelompok bersifat rahasia dan hanya diketahui oleh anggota kelompok tersebut. Menurut Prayitno (2012) layanan konseling kelompok merupakan layanan yang membantu remaja dalam pembahasan dan pengentasan masalah yang dialami sesuai dengan tuntutan karakter cerdas yang terpuji melalui dinamika kelompok. Melalui layanan konseling kelompok, anggota kelompok akan memperoleh tujuan yakni terkembangkannya perasaan dan terpecahkannya masalah individu. Sehingga anggota kelompok dapat memaknai kehidupannya lebih baik lagi.

\section{SIMPULAN DAN SARAN}


Keluarga bisa dikatakan ideal apabila masih dapat memberikan hal-hal yang diperlukan bagi proses tumbuh kembang anak. Keluarga memiliki peran penting bagi perkembangan remaja, apabila terjadi suatu permasalahan dalam maka hal tersebut akan berpengaruh terhadap kesejahteraan psikologis remaja. Kondisi yang tidak harmonis antara orangtua sehingga membuat kondisi keluarga menjadi broken home menimbulkan keadaan yang tidak diinginkan terhadap diri remaja. Remaja akan merasakan dampak secara psikis dari kondisi keluarga yang broken home, mereka akan merasakan kemarahan, takut, tertekan, dan merasa bersalah. Hal ini berakibat pada turunnya kesejahteraan psikologis (psychological well-being) remaja dikarenakan kegagalan dalam menjalankan peran dan tanggung jawab yang mereka emban. Sebagai remaja hendaknya perlu mencapai kesejahteraan psikologis yang baik agar dapat mencapai tugas-tugas perkembangannya.

Semoga kedepannya peningkatan, pengembangan, dan optimalisasi layanan bimbingan dan konseling untuk mengatasi kondisi psychological well-being dapat terselenggara dengan optinal, perlunya layanan bimbingan dan konseling untuk meningkatkan kondisi psychological well-being bagi remaja broken home agar ia mampu menerima diri dan kehidupannya di kemudian hari. Selanjutnya kerjasama antara guru dan orang tua juga bisa diupayakan sebagai salah satu cara untuk memfungsikan peran kedua orang tua dalam keluarga.

\section{REFERENSI}

Aritonang, N. N. (2019). Gambaran Perilaku Percobaan Bunuh Diri pada Remaja Putri yang Broken Home. Jurnal STINDO Profesional, V(2), 48-58.

Asiyah, A. (2017). Peran Keluarga Dalam Mendidik Anak. At-Ta'lim: Media Informasi Pendidikan Islam, 15(1), 166-185.

Awaliyah, A., \& Listiyandini, R. A. (2017). Pengaruh Rasa Kesadaran terhadap Kesejahteraan Psikologis Pada Mahasiswa. Jurnal Psikogenesis, 5(2), 89-101.

Aziz, M. (2019). Perilaku Sosial Anak Remaja Korban Broken Home dalam Berbagai Perspektif (Suatu Penelitian di SMPN 18 Kota Banda Aceh). Jurnal Al-Ijtimaiyyah: Media Kajian Pengembangan Masyarakat Islam, 1(1).

Bradburn, M. N. (1998). The Structure of Psychological Well Being. Chicago: Aldine Pub.Co.

Bupu, K. N., Nawaji, \& Iswahyudi, D. (2019). Pola Hidup Keluarga Broken Home. Prosiding Seminar Nasional Pendidikan Dan Pembelajaran Bagi Guru Dan Dosen, 3(1), 319-326.

Busra, A. (2019). Peranan Orang Tua Terhadap Pembinaan Akhlak Anak. Al-wardah, 12(2), 123-130.

Chaplin, J. P. (2011). Kamus Lengkap Psikologi (14th ed.). Jakarta: Raja Grafindo Persada.

Donnalo, R. S. (2020). Implementasi Pemuridan Kontekstual dalam Menanamkan Nilai Nilai Pendidikan Karakter Bagi Anak Usia Dini.

Echolis, J. M. (2020). Pola Asuh Orangg Tua Dalam Membantu Anak Membangun Disiplin Diri. Jakarta: Rineka Cipta.

Ermayanti, S., \& Abdullah, S. M. (2007). Hubungan antara persepsi terhadap dukungan sosial dengan penyesuaian diri pada masa pensiun. Jurnal InSight, 5, 148-162.

Goode, W. J. (2007). Sosiologi Keluarga. Jakarta: Bumi Aksara. 
Harimukthi, M. T., \& Dewi, K. S. (2017). Eksplorasi kesejahteraan psikologis individu dewasa awal penyandang tunanetra. Jurnal Psikologi Undip.

Hasan, M. (2012). Bahan Ajar Psikologi Konseling Keluarga. Padang: UNP Press.

Hasanah, S., Sahara, E., Sari, I. P., Wulandari, S., \& Hutasuhut, K. P. (2017). Broken Home pada Remaja dan Peran Konselor. Jurnal Riset Tindakan Indonesia, 2(2), 1-6.

Indriani, N. F. (2008). Dampak Psikologis Perceraian Orangtua terhadap Anak. Semarang.

Indryawati, R. (2014). Kesejahteraan psikologis guru yang mendapatkan sertifikasi. Jurnal Psikologi, 7(2).

Ischak, M. (2019). Upaya Perempuan Pembudidaya Rumput Laut dalam Meningkatkan Kesejahteraan Keluarga di Desa Pitusunggu Kecamatan Marang Kabupaten Pangkep. Universitas Islam Negeri Alauddin Makassar.

Kertapati, Y. (2019). Tugas Kesehatan Keluarga dan Tingkat Kemandirian Keluarga di Wilayah Pesisir Kota Surabaya. Jurnal Ilmiah Keperawatan, 14(1).

Linawati, R. A., \& Desiningrum, D. R. (2018). Hubungan antara religiusitas dengan psychological well-being pada siswa smp Muhammadiyah 7 Semarang. Empati, 6(3), 105-109.

Muthahari, A. H. (2019). Peran Yayasan Odesa dalam meningkatkan kesejahteraan keluarga: Studi deskriptif di Desa Cikadut, Kecamatan Cimenyan, Kabupaten Bandung. UIN Sunan Gunung Djati Bandung.

Na'imah, K. (2019). Kedisiplinan Pada Anak Panti Asuhan Ditinjau Dari Latar Belakang Keluarga (Studi Kasus Di Unit Pelaksanaan Teknis Pelayanan Sosial Asuhan Anak (UPT PSAA) Trenggalek). IAIN Kediri.

Nasri, S. A., Nisa, H., \& Karjuniwati, K. (2018). Bagaimana Remaja Memaafkan Perceraian Orang Tuanya: Sebuah Studi Fenomenologis. Seurune: Jurnal Psikologi UNSYIAH, $1(2), 102-120$.

Pangastuti, B., \& Sawitri, D. R. (2015). Hubungan Antara Konflik Peran Pekerjaankeluarga Dengan Kesejahteraan Psikologis Pada Anggota Kowad Di Kodam Iv/diponegoro. Empati, 4(2), 203-208.

Papalia, D. E., Olds, S. W., \& Feldman, R. D. (2008). Human Development. Jakarta: Prenada Media Group.

Prabowo, A. (2016). Kesejahteraan psikologis remaja di sekolah. Jurnal Ilmiah Psikologi Terapan, 4(2), 246-260.

Pratama, R., Syahniar, S., \& Karneli, Y. (2016). Perilaku Agresif Siswa dari Keluarga Broken Home. Konselor, 5(4).

Prayitno. (2012). Jenis Layanan dan Kegiatan Pendukung Konseling. Padang: UNP.

Prayitno, \& Amti, E. (2004). Dasar-dasar Bimbingan dan Konseling. Jakarta: Rineka Cipta.

Ramadhani, T., Djunaedi, \& Sismiati, A. (2016). Kesejahteraan Psikologis (Psychological Well- Being) Siswa Yang Orangtuanya Bercerai (Studi Deskriptif yang Dilakukan pada Siswa di SMK Negeri 26 Pembangunan Jakarta) Abstrak. Insight: Jurnal Bimbingan Konseling, 5(1), 108-115.

Riandana, Y. H. (2016). Hubungan Dukungan Sosial Keluarga dengan Psychological Well-Being (PWB) pada Lansia di GKJ Purbalingga. Universitas Kristen Satya Wacana.

Rofiqah, T., \& Sitepu, H. (2019). Bentuk Kenakalan Remaja sebagai Akibat Broken Home dan Implikasinya dalam Pelayanan Bimbingan Konseling. Jurnal KOPASTA, 6(2), 
99-107.

Ryff, C. D, Keyes, C. . (1995). The Structure of Psychological Well -Being Revisited. Journal of Personality and Social Psychologi, 69, 719-727.

Ryff, C. D. (1989). Happiness is everything, or is it? Exploration on the meaning of psychological well being. Journal of Personality and Social Psychologi, 57, 1069-1081.

Ryff, C. D., \& Keyes, C. L. M. (1995). The Structure of Psychological Well-Being Revisited. 69(4), 719-727.

Santrock, W. J. (2003). Adolescence Perkembangan Remaja. Jakarta: Erlangga.

Schmutte, P. S., \& Ryff, C. D. (1997). Personality and well-being: reexamining methods and meanings. Journal of Personality and Social Psychology, 73(3), 549.

Sobur, A. (1991). Anak Masa Depan. Bandung: Angkasa.

Sodikin, S. (2019). Literasi Media di Lingkungan Keluarga Dalam Mencegah Radikalisme Persepektif Al-Qur'an. Matan: Journal of Islam and Muslim Society, 1(1), 30-38.

Soraya, N. (2013). Perilaku sosial wanita muda pasca perceraian di Kecamatan Mojoroto Kota Kediri. Universitas Islam Negeri Maulana Malik Ibrahim.

Viitpoom, K., \& Saat, H. (2016). Psychological well-being of students in Estonia: Perspectives of students, parents, and teachers. In International Handbook of Psychological Well-Being in Children and Adolescents (pp. 51-59). Springer.

Wells, I. E. (2010). Psychology of emotions, motivations and actions: Psychological wellbeing. New York: Nova Science Publisher, Inc, 6(9), 111334.

Willis, S. S. (2013). Konseling Keluarga. Bandung: Alfabeta.

Yuliani, I. (2018). Konsep Psychological Well-Being Serta Implikasinya dalam Bimbingan dan Konseling. Journal of Innovative Couseling: Theory, Practice \& Research, 2(2), 51-56.

Yunistiati, F., Djalali, M. A. ad, \& Farid, M. (2014). Keharmonisan keluarga, konsep diri dan interaksi sosial remaja. Persona: Jurnal Psikologi Indonesia, 3(01).

Yusuf, S. (2009). Program Bimbingan dan Konseling di Sekolah. Bandung: Rizky Press.

Zulhaini, Z. (2019). Peranan Keluarga dalam Menanamkan Nilai-nilai Pendidikan Agama Islam Kepada Anak. Al-Hikmah (Jurnal Pendidikan Dan Pendidikan Agama Islam), 1(1), $1-15$. 